\title{
Development and evaluation of the Dutch Healthy Diet index 2015
}

\author{
Moniek Looman ${ }^{1, *}$, Edith JM Feskens ${ }^{1}$, Mariëlle de Rijk ${ }^{1}$, Saskia Meijboom ${ }^{1}$, \\ Sander Biesbroek ${ }^{2}$, Elisabeth HM Temme ${ }^{2}$, Jeanne de Vries $^{1}$ and Anouk Geelen ${ }^{1}$ \\ 'Division of Human Nutrition, Wageningen University \& Research, PO Box 17, 6700 AA Wageningen, \\ The Netherlands: ${ }^{2}$ Centre for Nutrition, Prevention and Health Services, National Institute for Public Health and \\ the Environment (RIVM), Bilthoven, The Netherlands
}

Submitted 17 January 2017: Final revision received 23 March 2017: Accepted 11 April 2017: First published online 19 June 2017

\begin{abstract}
Objective: To update the Dutch Healthy Diet index, a measure of diet quality, to reflect adherence to the Dutch dietary guidelines 2015 and to evaluate against participants' characteristics and nutrient intakes with the score based on $24 \mathrm{~h}$ recall (24hR) data and FFQ data.

Design: The Dutch Healthy Diet index 2015 (DHD15-index) consists of fifteen components representing the fifteen food-based Dutch dietary guidelines of 2015 . Per component the score ranges between 0 and 10 , resulting in a total score between 0 (no adherence) and 150 (complete adherence).

Setting: Wageningen area, the Netherlands, 2011-2013.

Subjects: Data of 885 men and women, aged 20-70 years, participating in the longitudinal NQplus study, who filled out two $24 \mathrm{hR}$ and one FFQ, were used. Results: Mean (SD) score of the DHD15-index was $68.7(16 \cdot 1)$ for men and 79.4 (16.0) for women. Significant inverse trends were found between the DHD15-index and BMI, smoking, and intakes of energy, total fat and saturated fat. Positive trends were seen across sex-specific quintiles of the DHD15-index score with energy-adjusted micronutrient intakes. Mean DHD15-index score of the FFQ data was 15.5 points higher compared with $24 \mathrm{hR}$ data, with a correlation coefficient of 0.56 between the scores. Observed trends of the DHD15-index based on FFQ with participant characteristics, macronutrient and energy-adjusted micronutrient intakes were similar to those with the DHD15-index based on $24 \mathrm{hR}$. Conclusions: The DHD15-index score assesses adherence to the Dutch dietary guidelines 2015 and indicates diet quality. The DHD15-index score can be based on $24 \mathrm{hR}$ data and on FFQ data.
\end{abstract}

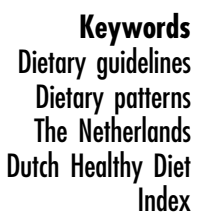

The Dutch Healthy Diet index (DHD-index) is a measure of diet quality as it assesses adherence to the Dutch dietary guidelines published in 2006 by the Health Council of the Netherlands ${ }^{(1)}$. The DHD-index has been used in a variety of applications, including intervention monitoring and epidemiological research ${ }^{(2-4)}$. A higher DHD-index score has been associated with more nutrient-dense diets ${ }^{(5)}$ and lower risk of mortality ${ }^{(6)}$, but not with $\mathrm{CVD}^{(7)}$ or qualityadjusted life years $^{(8)}$.

In 2015, the Health Council of the Netherlands published an updated version of the Dutch dietary guidelines, based upon the latest scientific evidence ${ }^{(9)}$. Where the Dutch dietary guidelines of 2006 consisted of food-based and nutrient-based guidelines (e.g. vegetables, fruit, fibre and saturated fat), the 2015 guidelines are completely food-based (e.g. wholegrain products, red and processed meat, and fats and oils) ${ }^{(10)}$. Due to this revision of the Dutch dietary guidelines the DHD-index needed to be updated. Therefore, we developed the Dutch Healthy Diet index 2015 (DHD15-index) as a tool to measure adherence to the Dutch dietary guidelines of 2015. In the present paper we describe the development of this new score and examine associations of the DHD15-index with participants' characteristics and energy, macro- and micronutrient intakes based on $24 \mathrm{~h}$ recall $(24 \mathrm{hR})$ data. Additionally, the DHD15-index score derived from FFQ data is compared with the DHD15-index score derived from the $24 \mathrm{hR}$ data to assess comparability of the index when based on different dietary assessment instruments.

\section{Methods}

\section{Study design and population}

The Nutrition Questionnaires plus (NQplus) study is a longitudinal study on diet and health in the general Dutch 
population. The NQplus study has been described elsewhere $^{(11)}$. Briefly, between May 2011 and December 2013, a total of 2048 men and women were included, all randomly selected inhabitants of the cities of Wageningen, Renkum, Ede, Arnhem and Veenendaal, which are located in the central part of the Netherlands. Inclusion criteria were age 20-70 years and being able to speak and write Dutch.

Baseline measurements consisted of dietary assessment (including supplement use) with multiple $24 \mathrm{hR}$ and FFQ, anthropometric measurements (including height and body weight measurements), blood sampling via a venepuncture, a $24 \mathrm{~h}$ urine collection and general questionnaires (including age, sex, highest achieved education level (low: primary school, vocational or lower general secondary education; moderate: higher secondary education or intermediate vocational training; high: higher vocational education or university) and smoking (yes/no)). Participants with data of least two telephoneadministered $24 \mathrm{hR}$ and a baseline FFQ ( $n$ 885) were included for the current analysis.

\section{Dietary assessment}

\section{$24 \mathrm{~b}$ recalls}

The $24 \mathrm{hR}$ was administered by means of a telephone interview by trained dietitians of the Division of Human Nutrition of Wageningen University. The dietitian made an unannounced phone call to the participant and asked about the foods and drinks consumed the previous day according to a standardized protocol based on the five-step multiplepass method ${ }^{(12)}$. Recalls were at least one month apart and the first two completed $24 \mathrm{hR}$ were used for the present analyses. Energy and nutrient intakes were estimated using the 2011 Dutch Food Composition Table ${ }^{(13)}$.

\section{FFQ}

A 180-item semi-quantitative FFQ was used to assess usual dietary intake and was previously evaluated for energy intake, macronutrients, dietary fibre and selected vitamins ${ }^{(14,15)}$. Answer categories for frequency questions ranged from 'not in this month' to ' $6-7 \mathrm{~d} /$ week', and portion sizes were estimated using natural portions (bread shapes) and commonly used household measures (e.g. spoon and cup). Average daily nutrient intakes were calculated by multiplying frequency of consumption by portion size and nutrient content per gram using the 2011 Dutch Food Composition Table ${ }^{(13)}$. We estimated the same micronutrient intakes as for the $24 \mathrm{hR}$, except for Fe and $\mathrm{Mg}$ as the FFQ was not developed to estimate these intakes. The FFQ was administered online using the opensource survey tool Limesurvey.

\section{Development of the DHD15-index}

In Table 1 an overview of the components and their cut-off and threshold values can be found. For all fifteen components a maximum of 10 points could be allotted, resulting in a total score ranging from 0 to 150 points. The components vegetables, fruit, legumes, nuts, fish and tea are adequacy components, and the components red meat, processed meat, sweetened beverages and fruit juices, sodium and alcohol are moderation components. The component dairy is an optimum component with an optimal range of intakes, whereas the fats and oils component is defined as a ratio component to reflect replacement of intake of less desired foods with healthier options in that food group. The coffee component is defined as a qualitative component based on type of coffee. The wholegrain products component is scored based on two sub-components as there are two guidelines for grain products: an adequacy component for wholegrain consumption and a ratio component to reflect replacement of refined grain products by wholegrain products.

Cut-off values represent the minimum (for adequacy components) and maximum (for moderation components) required amount of consumption awarded with 10 points. The threshold values represent the lowest level of intake awarded with 0 points (for moderation components only). For adequacy components, no intake is awarded with 0 points. Intakes between the cut-off and threshold value are scored proportionally. In the text below, for each guideline/component the included food groups, explanation of cut-off and threshold values and adaptations for estimation with an FFQ are discussed, if applicable. This is followed by an explanation of the scoring per type of component.

\section{Vegetables}

The first component is based on the recommendation to consume at least $200 \mathrm{~g}$ of vegetables daily. Foods for this component are vegetables including frozen and canned vegetables, peas and salads, but not legumes or potatoes. The cut-off was set at $200 \mathrm{~g}$ as quantified in the guideline.

\section{Fruit}

The second component is based on the recommendation to consume at least $200 \mathrm{~g}$ of fruit daily. Fresh fruit intake was included for this component, but not dried fruit as this has a relatively high energy and sugar content compared with fresh fruit ${ }^{(16)}$. In contrast to the previous DHD-index, fruit juices are no longer included. The cut-off was set at $200 \mathrm{~g}$ as quantified in the guideline.

\section{Wholegrain products}

The third component was based on two guidelines regarding wholegrain foods and therefore scored with two sub-components. The first sub-component was based on the recommendation to consume at least $90 \mathrm{~g}$ of wholegrain products daily. The cut-off was set at $90 \mathrm{~g}$ as quantified in the guideline. The second sub-component is based on the recommendation to replace refined cereal products by wholegrain products and is scored as a ratio component obtained by dividing intake of wholegrain 
Table 1 Components and Dutch dietary guidelines of the Dutch Healthy Diet index 2015 (DHD15-index) and their threshold (minimum score) and cut-off (maximum score) values

\begin{tabular}{|c|c|c|c|c|c|}
\hline & Component & $\begin{array}{c}\text { Component } \\
\text { type }\end{array}$ & Dutch dietary guidelines 2015 & Minimum score ( $=0$ points) & Maximum score (=10 points) \\
\hline 1. & Vegetables & A & Eat at least $200 \mathrm{~g}$ of vegetables daily & $0 \mathrm{~g} / \mathrm{d}$ & $\geq 200 \mathrm{~g} / \mathrm{d}$ \\
\hline 2. & Fruit & A & Eat at least $200 \mathrm{~g}$ of fruit daily & $0 \mathrm{~g} / \mathrm{d}$ & $\geq 200 \mathrm{~g} / \mathrm{d}$ \\
\hline \multirow[t]{3}{*}{3.} & \multirow[t]{3}{*}{ Wholegrain products $\dagger$} & A & a. Eat at least $90 \mathrm{~g}$ of wholegrain products daily & $0 \mathrm{~g} / \mathrm{d}$ & $\geq 90 \mathrm{~g} / \mathrm{d}$ \\
\hline & & \multirow[t]{2}{*}{$\mathrm{R}$} & \multirow[t]{2}{*}{ b. Replace refined cereal products by wholegrain products } & $\begin{array}{l}\text { No consumption of wholegrain products } \\
\text { OR }\end{array}$ & $\begin{array}{l}\text { No consumption of refined products } \\
\text { OR }\end{array}$ \\
\hline & & & & Ratio of whole grains to refined grains $\leq 0.7$ & $\begin{array}{l}\text { Ratio of whole grains to refined } \\
\text { grains } \geq 11\end{array}$ \\
\hline 4. & Legumes & A & Eat legumes weekly & $0 \mathrm{~g} / \mathrm{d}$ & $\geq 10 \mathrm{~g} / \mathrm{d}$ \\
\hline 5. & Nuts & A & Eat at least $15 \mathrm{~g}$ of unsalted nuts daily & $0 \mathrm{~g} / \mathrm{d}$ & $\geq 15 \mathrm{~g} / \mathrm{d}$ \\
\hline 6. & Dairy $\ddagger$ & $\mathrm{O}$ & Eat a few portions of dairy produce daily, including milk or yoghurt & $0 \mathrm{~g} / \mathrm{d} O R \geq 750 \mathrm{~g} / \mathrm{d}$ & $300-450 \mathrm{~g} / \mathrm{d}$ \\
\hline 7. & Fish§ & A & Eat one serving of fish weekly, preferably oily fish & $0 \mathrm{~g} / \mathrm{d}$ & $\geq 15 \mathrm{~g} / \mathrm{d}$ \\
\hline 8. & Tea & A & Drink three cups of black or green tea daily & $0 \mathrm{~g} / \mathrm{d}$ & $\geq 450 \mathrm{~g} / \mathrm{d}$ \\
\hline \multirow[t]{2}{*}{9.} & \multirow[t]{2}{*}{ Fats and oils } & \multirow[t]{2}{*}{$\mathrm{R}$} & \multirow[t]{2}{*}{$\begin{array}{l}\text { Replace butter, hard margarines and cooking fats by soft } \\
\text { margarines, liquid cooking fats and vegetable oils }\end{array}$} & $\begin{array}{l}\text { No consumption of soft margarines, liquid } \\
\text { cooking fats and vegetable oils } \\
\text { OR }\end{array}$ & $\begin{array}{l}\text { No consumption of butter, hard } \\
\text { margarines and cooking fats } \\
\text { OR }\end{array}$ \\
\hline & & & & $\begin{array}{l}\text { Ratio of liquid cooking fats to solid cooking } \\
\text { fats } \leq 0.6\end{array}$ & $\begin{array}{l}\text { Ratio of liquid cooking fats to solid } \\
\text { cooking fats } \geq 13\end{array}$ \\
\hline 10. & Coffee & Q & Replace unfiltered coffee by filtered coffee & Any consumption of unfiltered coffee & $\begin{array}{l}\text { Consumption of only filtered coffee } \\
\text { OR } \\
\text { No coffee consumption }\end{array}$ \\
\hline 11. & Red meat & M & Limit consumption of red meat & $\geq 100 \mathrm{~g} / \mathrm{d}$ & $\leq 45 \mathrm{~g} / \mathrm{d}$ \\
\hline 12. & Processed meat & M & Limit consumption of processed meat & $\geq 50 \mathrm{~g} / \mathrm{d}$ & $0 \mathrm{~g} / \mathrm{d}$ \\
\hline 13. & $\begin{array}{l}\text { Sweetened beverages } \\
\text { and fruit juices }\end{array}$ & M & Limit consumption of sweetened beverages and fruit juices & $\geq 250 \mathrm{~g} / \mathrm{d}$ & $0 \mathrm{~g} / \mathrm{d}$ \\
\hline 14. & Alcohol & M & $\begin{array}{l}\text { If alcohol is consumed at all, intake should be limited to one Dutch } \\
\text { unit ( } 10 \mathrm{~g} \text { ethanol) daily }\end{array}$ & $\begin{array}{l}\text { Women: } \geq 20 \mathrm{~g} \text { ethanol } / \mathrm{d} \\
\text { Men: } \geq 30 \mathrm{~g} \text { ethanol } / \mathrm{d}\end{array}$ & $\begin{array}{l}\text { Women: } \leq 10 \mathrm{~g} \text { ethanol } / \mathrm{d} \\
\text { Men: } \leq 10 \mathrm{~g} \text { ethanol } / \mathrm{d}\end{array}$ \\
\hline 15. & Salt & M & Limit consumption of table salt to $6 \mathrm{~g}$ daily & $\geq 3.8 \mathrm{~g} \mathrm{Na} / \mathrm{d}$ & $\leq 1.9 \mathrm{~g} \mathrm{Na} / \mathrm{d}$ \\
\hline
\end{tabular}

${ }^{*}$ Type of component: A, adequacy component; M, moderation component; O, optimum component; Q, qualitative component; R, ratio component.

†This component comprises two sub-components ( $a$ and $b$ ). Each sub-component has a maximum score of 5 points.

łMaximum of $40 \mathrm{~g}$ cheese can be included.

\$Maximum of $4 \mathrm{~g}$ lean fish can be included. 
products by intake of refined cereal products. There was no quantitative recommendation, nor information about the level of intake of refined cereal products associated with adverse health effects upon which to base the cut-off or threshold value. Therefore, we used the 15 th percentile of the intake distribution of the Dutch reference population based on two-day averages (Dutch National Food Consumption Survey 2007-2010 $0^{(17)}$ ) as (arbitrary) cut-off value. The threshold value was equal to the 85th percentile as we also did for the DHD-index. The maximum score for both sub-components is 5 points. By adding the scores of the two sub-components, the score for wholegrain products is obtained. Included food groups were cereal products used as staple component of the diet (e.g. bread products, bread replacement products, muesli, pasta and rice), but no snacks made of cereal products such as biscuits. Foods were categorized as wholegrain product if they contained at least $25 \%$ wholegrain flour; otherwise they were categorized as refined grain product.

\section{Legumes}

The fourth component is based on the recommendation to consume legumes weekly. As intakes in the score are expressed per day, one portion of legumes $\left(60 \mathrm{~g}^{(16)}\right)$ was divided by 7 and rounded to $10 \mathrm{~g} / \mathrm{d}$ to obtain the cut-off value. Included food groups are pulses, lentils, beans and chickpeas, but not peas and peanuts ${ }^{(18)}$.

\section{Nuts}

The fifth component assesses unsalted nut consumption and is based on the recommendation to consume at least $15 \mathrm{~g}$ of unsalted nuts daily. The cut-off was set at $15 \mathrm{~g}$ as quantified in the guideline. As stated in the guideline, only unsalted nuts were included in this component. However, the FFQ did not distinguish between unsalted and salted nuts. Therefore, total nut consumption was included for this component for the FFQ-based DHD15-index score.

\section{Dairy}

The sixth component, dairy, is based on the recommendation to consume a few portions of dairy produce daily, including milk and yoghurt. Included food groups are milk, milk products, yoghurt, cheese, cream, custard and porridge prepared with dairy. This component was interpreted as an optimum component. Two to three portions daily, with a portion size of $150 \mathrm{~g}$ per portion (Netherlands Nutrition Centre), resulted in the optimum range of intake $(300-450 \mathrm{~g} / \mathrm{d})$ and a score of 10 points. An intake of more than two times the average recommended amount was set as threshold value. Cheese intake was also included in total dairy intake, but limited to a maximum of $40 \mathrm{~g}$ (as set by the Netherlands Nutrition Centre) to account for differences in portion sizes between milk and cheese. Furthermore, a limitation in cheese intake ensures that the maximum score for dairy can only be obtained when milk or yoghurt products are consumed, as specified in the recommendation of the Health Council of the Netherlands.

\section{Fish}

The seventh component, fish, is based on the recommendation to consume one portion of fish weekly, preferably oily fish. One portion of fish $\left(100 \mathrm{~g}^{(16)}\right)$ was divided by 7 and rounded to obtain the cut-off value of $15 \mathrm{~g} / \mathrm{d}$ for fish. As the recommendation favours intake of oily fish, a maximum for lean fish of $4 \mathrm{~g} / \mathrm{d}$ was included. This maximum was derived from the ratio of three times oily fish to one times lean fish (per month) as set by the Netherlands Nutrition Centre.

\section{Tea}

The eighth component is based on the recommendation to consume three cups of black or green tea daily. Portion sizes set by the Netherlands Nutrition Centre were used to arrive at a cut-off value of $450 \mathrm{~g} / \mathrm{d}$ (equal to $450 \mathrm{ml} / \mathrm{d}$ ). As the FFQ does not distinguish between types of tea, total tea consumption was used for this component for the FFQ-based DHD15-index score.

\section{Fats and oils}

The ninth component is a ratio component based on the recommendation for fats and oils. The ratio is obtained by dividing intake of soft margarines, liquid cooking fats and vegetable oils by intake of butter, hard margarines and cooking fats. Similar to the ratio sub-component for whole grains, cut-off and threshold values were derived from the 15 th percentile and 85 th percentile of the intake distribution of the Dutch reference population ${ }^{(17)}$.

\section{Coffee}

The tenth component, coffee, is a quality component, based on type of coffee (filtered or unfiltered). Scoring for this component is, contrary to the other components, dichotomous. No consumption of unfiltered coffee or no consumption of coffee at all was set as criterion for the maximum score of 10 points, whereas any consumption of unfiltered coffee is awarded with 0 points. Because both the $24 \mathrm{hR}$ and FFQ do not distinguish between types of coffee consumed, the component score for coffee could not be assessed in the present study.

\section{Red meat}

The eleventh component, red meat, is based on the recommendation to limit red meat consumption. Included food products for this component are beef, pork, duck, pheasant, offal and game products. The Netherlands Nutrition Centre advises to consume less than $300 \mathrm{~g}$ of red meat weekly (about $45 \mathrm{~g} / \mathrm{d}$ ). The cut-off value was thus set at an intake of $45 \mathrm{~g} / \mathrm{d}$. The Health Council of the Netherlands indicated that with a consumption of $100 \mathrm{~g} / \mathrm{d}$ or more negative health effects were observed ${ }^{(19)}$. Consequently, the threshold value was set at an intake of $100 \mathrm{~g} / \mathrm{d}$. 


\section{Processed meat}

The twelfth component, processed meat, is based on the recommendation to limit consumption of processed meat. Both processed red meat and processed white meat are food groups included in this component. As the Health Council of the Netherlands indicated that especially consumption of processed meat should be limited, the cut-off value was set at no consumption. The Health Council of the Netherlands indicated that negative health effects of processed meat are observed at intakes of $50 \mathrm{~g} / \mathrm{d}$ or more ${ }^{(19)}$, and therefore this was set as threshold value.

\section{Sweetened beverages and fruit juices}

The thirteenth component was based on the recommendation to limit consumption of sweetened beverages and fruit juices. For this component, sugar-sweetened soft drinks, sugar-sweetened dairy drinks and fruit juices were included. No consumption was set as cut-off value and a consumption of $250 \mathrm{~g} / \mathrm{d}$ as threshold value, as consumption of more than $250 \mathrm{~g} / \mathrm{d}$ was found to be associated with weight gain $^{(20)}$.

\section{Alcohol}

The fourteenth component, alcohol, is based on the recommendation to limit consumption to one Dutch unit ( $10 \mathrm{~g}$ ethanol/d), if alcohol is consumed at all. This $10 \mathrm{~g}$ ethanol/d was set as cut-off value. Negative health effects occur at different intakes for men and women ${ }^{(21)}$, therefore the threshold value was differentiated by sex. For women an intake of $20 \mathrm{~g}$ ethanol/d was associated with negative health effects, and thus this intake was used as threshold value, whereas for men this was set at $30 \mathrm{~g}$ ethanol/d.

\section{Salt}

The last component, salt, is based on the recommendation to consume less than $6 \mathrm{~g}$ of table salt daily. This corresponds to a recommended consumption of $2 \cdot 4 \mathrm{~g}$ of $\mathrm{Na}$ daily or less. For this component the Na content of all consumed foods was summed to obtain $\mathrm{Na}$ intake per day. Ideally, salt consumption is assessed with $\mathrm{Na}$ content based on a $24 \mathrm{~h}$ urine collection. However, this was not available for the Dutch reference population. Therefore, the threshold value is based on the intake distribution of the Dutch reference population assessed with two $24 \mathrm{hR}$. With $\mathrm{Na}$ intakes based on $24 \mathrm{hR}$ and especially FFQ, salt added during cooking and at the dinner table is not taken into account. The contribution of these sources is assumed to be on average $20 \%$ of total $\mathrm{Na}$ intake in the Netherlands ${ }^{(22)}$. In most studies there are no data available on the amount of salt added during cooking and at the dinner table. Therefore we adjusted the cut-off value representing the recommended maximum $\mathrm{Na}$ intake by $20 \%$, to compensate for this.

\section{Scoring}

For the adequacy components vegetables, fruit, nuts, legumes, nuts, fish and tea, the minimum score was given when there was no consumption of this component.

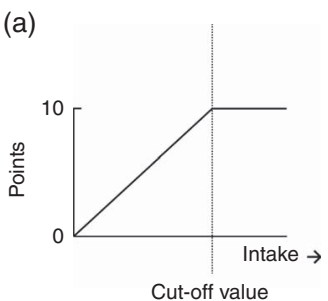

(c)

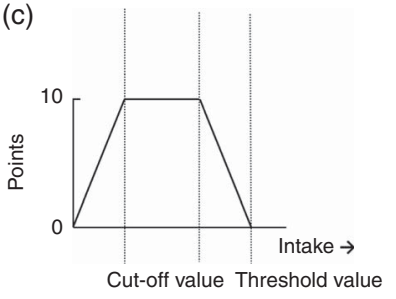

(b)

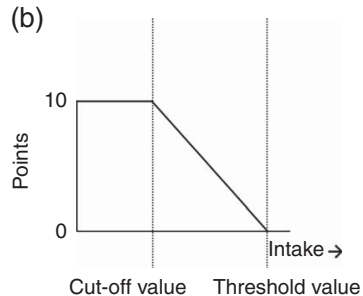

(d)

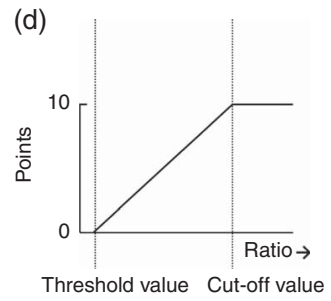

Fig. 1 Graphic presentation of scoring for the DHD15-index for the different type of components: (a) adequacy component; (b) moderation component; (c) optimum component; (d) ratio component

Intake equal to the cut-off value or higher was given the maximum score of 10 points. The score for intake between zero and the cut-off value was calculated by dividing the reported intake by the cut-off value and subsequently multiplying the obtained ratio by 10 (Fig. 1(a)). For the moderation components red meat, processed meat, sweetened beverages and fruit juices, sodium and alcohol, 0 points were assigned if intake was above the threshold value. 10 points were assigned if intake was equal to or lower than the cut-off value. The score for intake between the threshold and cut-off values was calculated by dividing the difference between the intake and the cut-off value by the difference between the threshold value and the cut-off value. This ratio was subsequently multiplied by 10 . The obtained score was subtracted from 10 to obtain the component score, as the score for moderation components has to decrease when intake increases (Fig. 1(b)). The maximum score for the optimum component dairy was assigned if intake was within the given range. No consumption was scored with the minimum score of 0 points. Intake lower than the cut-off value was scored by dividing the reported intake by the lower cut-off value of the range and subsequently multiplying the obtained ratio by 10 . Intake between the higher cut-off value of the range and the threshold value was scored by dividing the difference between the intake and the cut-off value by the difference between the threshold value and the cut-off value. This ratio was subsequently multiplied by 10 . The obtained score was subtracted from 10 to ensure that the score decreases when intake increases. For intake above the threshold value the minimum score of 0 points was given (Fig. 1(c)). Cut-off values and threshold values for the ratio components were set for the calculated ratios, instead of intakes. The maximum score of 10 points was assigned if the ratio was higher than the cut-off value. The minimum score of 0 points was assigned if the ratio 
was lower than the threshold value. The score for intake between the cut-off and threshold values was calculated by dividing the difference between the ratio and the threshold value by the difference between the cut-off and threshold value (Fig. 1(d)).

\section{Statistical analysis}

All food, energy and nutrient intakes assessed by $24 \mathrm{hR}$ were averaged over two days before being used to score individual dietary intakes. DHD15-index scores reported in the present paper are based on $24 \mathrm{hR}$ unless stated otherwise. Means across sex-specific quintiles of the DHD15-index score were tested using $P$ for trend calculated with general linear models. Macro- and micronutrient intakes are reported with and without energy adjustment. Adjusted macronutrient intakes are presented as energy percentage $(\mathrm{E} \%)$ and adjusted micronutrient intakes are presented as mean intakes per $4.2 \mathrm{MJ}$.

Concordance of ranking of participants with the DHD15index scores based on $24 \mathrm{hR}$ data and FFQ data was studied by analysing correlations between the scores and crossclassification of quintiles. Partial correlation coefficients were calculated for the DHD15-index score and its components based on the $24 \mathrm{hR}$ data and the FFQ data, adjusting for energy intake assessed by the $24 \mathrm{hR}$. Pearson correlations were used for normally distributed variables and Spearman correlations for skewed variables. The 95\% confidence intervals were calculated using Fisher's Z-transformation. The Wilcoxon signed-rank test was used to test differences between medians. Cross-classification and Kendall's $\tau_{\mathrm{b}}$ coefficient were used to assess agreement of participants' ranking for the DHD15-index score based on $24 \mathrm{hR}$ data and on FFQ data. All statistical analyses were performed using the statistical software package SAS version 9.3 and a $P$ value of $<0.05$ was considered statistically significant.

\section{Results}

Mean age of the population was 54.0 (SD 11.7) years and mean BMI was 25.9 (sD 4.0$) \mathrm{kg} / \mathrm{m}^{2}$. Fifty-three per cent of the population were men. Men were significantly older (mean 56.4 (SD 10.8) years) than women (mean 51.4 (SD 12.1) years) and their BMI was significantly higher (mean $26.4(\mathrm{SD} 3.5) \mathrm{kg} / \mathrm{m}^{2}$ ) than that of the women (mean 25.4 (sD 4.5$) \mathrm{kg} / \mathrm{m}^{2}$ ). More than $60 \%$ of the population completed a level of higher education and less than $10 \%$ of the population was current smoker; this did not differ between men and women.

The mean DHD15-index score for the total population based on $24 \mathrm{hR}$ data was 73.7 (SD 16.9) points (Table 2). The total DHD15-index score was significantly higher for women than for men (mean difference of 10.7 points). The total DHD15-index score was normally distributed and ranged from 24.3 to 126.2 points. The highest mean component score was that for the component red meat followed by alcohol, whereas the lowest mean component score was observed for the component legumes followed by fish. Women had significantly higher (i.e. better) scores for the components vegetables, fruit, nuts, tea, red meat, processed meat, sweetened beverages and juices, alcohol and salt. Men scored significantly higher on the component wholegrain products. The DHD15-index score was positively correlated with the DHD-index based on the dietary guidelines of 2006 ( $\rho=0.62 ; P<0.001)$.

BMI and smoking were inversely associated with the DHD15-index (Table 3). Age and supplement use were positively associated with the DHD15-index score, whereas education was not associated with the index score. Participants with a higher DHD15-index score had a lower energy intake. Of the macronutrients, animal protein, added sugar, total fat and saturated fat were inversely

Table 2 Mean scores (and standard deviations) of the Dutch Healthy Diet index 2015 (DHD15-index) and its components in 885 Dutch men and women aged $20-75$ years*

\begin{tabular}{|c|c|c|c|c|c|c|c|}
\hline & \multicolumn{2}{|c|}{ Total } & \multicolumn{2}{|c|}{ Men } & \multicolumn{2}{|c|}{ Women } & \multirow{2}{*}{$\begin{array}{c}P \text { value } \\
\text { between sexest }\end{array}$} \\
\hline & Mean & SD & Mean & SD & Mean & SD & \\
\hline Vegetables & $6 \cdot 2$ & $3 \cdot 2$ & 5.9 & $3 \cdot 2$ & $6 \cdot 6$ & $3 \cdot 1$ & 0.001 \\
\hline Fruit & $6 \cdot 2$ & 3.7 & $5 \cdot 8$ & 3.8 & $6 \cdot 7$ & 3.5 & $<0.001$ \\
\hline Wholegrain products & $5 \cdot 7$ & 2.7 & $6 \cdot 0$ & 2.5 & $5 \cdot 5$ & 2.8 & 0.006 \\
\hline Dairy & $6 \cdot 0$ & $3 \cdot 2$ & 5.9 & $3 \cdot 2$ & $6 \cdot 2$ & $3 \cdot 3$ & 0.189 \\
\hline Fish & $2 \cdot 2$ & 3.8 & $2 \cdot 4$ & 4.0 & $2 \cdot 0$ & 3.6 & 0.447 \\
\hline Tea & $5 \cdot 8$ & $4 \cdot 0$ & $4 \cdot 7$ & 4.0 & $7 \cdot 1$ & 3.7 & $<0.001$ \\
\hline Fats and oils & $6 \cdot 2$ & 4.5 & $6 \cdot 2$ & 4.5 & $6 \cdot 1$ & 4.5 & 0.881 \\
\hline Red meat & $8 \cdot 6$ & $3 \cdot 0$ & $8 \cdot 2$ & $3 \cdot 3$ & 9.0 & 2.6 & $<0.001$ \\
\hline
\end{tabular}

*Dietary intakes are based on average intake of two $24 \mathrm{~h}$ recalls.

†Independent $t$ test comparing men and women for total DHD15-index score and Mann-Whitney $U$ test comparing men and women for the individual component scores.

‡DHD15-index score ranging from 0 to 140 points. 
Table 3 Distribution of characteristics, macronutrient and selected micronutrient intakes (means and standard deviations, or percentages) across sex-specific quintiles of the Dutch Healthy Diet index 2015 (DHD15-index) in 885 Dutch men and women aged 20-75 years*

\begin{tabular}{|c|c|c|c|c|c|c|c|c|c|c|c|}
\hline & \multicolumn{10}{|c|}{ Sex-specific quintile of DHD15-index } & \multirow[b]{2}{*}{$P$ for trenc } \\
\hline & \multicolumn{2}{|c|}{ Q1 ( $n$ 178) } & \multicolumn{2}{|c|}{ Q2 ( $n$ 178) } & \multicolumn{2}{|c|}{ Q3 ( $n$ 175) } & \multicolumn{2}{|c|}{ Q4 $(n$ 177) } & \multicolumn{2}{|c|}{ Q5 (n 177) } & \\
\hline Mean DHD15-index score & \multicolumn{2}{|c|}{51.8} & \multicolumn{2}{|c|}{64.0} & \multicolumn{2}{|c|}{$72 \cdot 7$} & \multicolumn{2}{|c|}{$80 \cdot 8$} & \multicolumn{2}{|c|}{$96 \cdot 0$} & \\
\hline Mean DHD-index score† & $40 \cdot 0$ & 8.9 & $44 \cdot 3$ & $9 \cdot 2$ & $49 \cdot 1$ & $9 \cdot 1$ & 53.3 & $9 \cdot 6$ & $58 \cdot 8$ & 8.7 & $<0.001$ \\
\hline Age (years) & 51.4 & 11.9 & 52.8 & 11.6 & 54.4 & $12 \cdot 3$ & 55.7 & $10 \cdot 6$ & 55.9 & 11.5 & $<0.001$ \\
\hline BMI $\left(\mathrm{kg} / \mathrm{m}^{2}\right)$ & $26 \cdot 7$ & 4.4 & $26 \cdot 3$ & 4.4 & $25 \cdot 9$ & 3.9 & $25 \cdot 8$ & 3.8 & $25 \cdot 0$ & 3.2 & $<0.001$ \\
\hline Supplements (\%) & \multirow{2}{*}{\multicolumn{2}{|c|}{34.3}} & \multirow{2}{*}{\multicolumn{2}{|c|}{41.0}} & \multirow{2}{*}{\multicolumn{2}{|c|}{40.6}} & \multicolumn{2}{|c|}{$46 \cdot 3$} & \multicolumn{2}{|c|}{$50 \cdot 1$} & 0.001 \\
\hline Education (\%)‡ & & & & & & & & & & & 0.346 \\
\hline Low & $7 \cdot 3$ & & $5 \cdot 1$ & & $9 \cdot 8$ & & $5 \cdot 1$ & & 3.4 & & \\
\hline Middle & 29.9 & & 29.4 & & 24.9 & & $32 \cdot 7$ & & 29.4 & & \\
\hline High & 63.7 & & 65.5 & & $65 \cdot 3$ & & $62 \cdot 2$ & & $67 \cdot 2$ & & \\
\hline \multirow{2}{*}{\multicolumn{12}{|c|}{ Macronutrient intakes }} \\
\hline & & & & & & & & & & & \\
\hline Energy $(\mathrm{MJ} / \mathrm{d})$ & $9 \cdot 3$ & $2 \cdot 4$ & 8.9 & $2 \cdot 1$ & 8.8 & $2 \cdot 2$ & 8.7 & $2 \cdot 1$ & 8.6 & 1.9 & $<0.001$ \\
\hline Protein $(\mathrm{g} / \mathrm{d})$ & $84 \cdot 8$ & $25 \cdot 6$ & 81.9 & $21 \cdot 7$ & $81 \cdot 3$ & $21 \cdot 1$ & 83.6 & $22 \cdot 4$ & $81 \cdot 1$ & $17 \cdot 0$ & 0.281 \\
\hline Protein (E\%) & $15 \cdot 6$ & $3 \cdot 1$ & $15 \cdot 8$ & $2 \cdot 7$ & $16 \cdot 0$ & 3.1 & $16 \cdot 7$ & 3.0 & $16 \cdot 5$ & 2.9 & $<0.001$ \\
\hline Vegetable protein $(\mathrm{g} / \mathrm{d})$ & $32 \cdot 4$ & $11 \cdot 1$ & $32 \cdot 9$ & $10 \cdot 3$ & $33 \cdot 2$ & $10 \cdot 8$ & $33 \cdot 7$ & $10 \cdot 6$ & $37 \cdot 1$ & $11 \cdot 2$ & $<0.001$ \\
\hline Animal protein $(\mathrm{g} / \mathrm{d})$ & $52 \cdot 2$ & 21.5 & $49 \cdot 0$ & $18 \cdot 3$ & 48.0 & $17 \cdot 1$ & $50 \cdot 0$ & $19 \cdot 6$ & 44.1 & $14 \cdot \overline{3}$ & $<0.001$ \\
\hline Carbohydrate $(\mathrm{g} / \mathrm{d})$ & 236 & 70 & 225 & 66 & 224 & 62 & 225 & 63 & 222 & 58 & 0.077 \\
\hline Carbohydrate (E\%) & $43 \cdot 3$ & $7 \cdot 3$ & $43 \cdot 2$ & $7 \cdot 1$ & $43 \cdot 8$ & 7.0 & 44.6 & $6 \cdot 8$ & 44.4 & 6.5 & 0.035 \\
\hline Added sugar $(\mathrm{g} / \mathrm{d})$ & $53 \cdot 3$ & $31 \cdot 0$ & $47 \cdot 2$ & $26 \cdot 9$ & $47 \cdot 0$ & $28 \cdot 1$ & $43 \cdot 2$ & $27 \cdot 6$ & $37 \cdot 7$ & 23.0 & $<0.001$ \\
\hline Fibre $(g / d)$ & $19 \cdot 8$ & $6 \cdot 6$ & 21.4 & 6.9 & $22 \cdot 5$ & $6 \cdot 7$ & 24.4 & $6 \cdot 9$ & $27 \cdot 0$ & $7 \cdot 7$ & $<0.001$ \\
\hline Total fat $(\mathrm{g} / \mathrm{d})$ & $86 \cdot 6$ & $26 \cdot 8$ & 82.4 & 24.7 & $80 \cdot 7$ & $26 \cdot 5$ & $78 \cdot 0$ & $25 \cdot 8$ & $77 \cdot 7$ & 23.7 & $<0.001$ \\
\hline Total fat $(\mathrm{E} \%)$ & 33.9 & 5.4 & 33.9 & $5 \cdot 3$ & 33.4 & $5 \cdot 8$ & $32 \cdot 8$ & $5 \cdot 7$ & $33 \cdot 1$ & $5 \cdot 8$ & 0.042 \\
\hline Saturated fat $(g / d)$ & 32.9 & $10 \cdot 7$ & $30 \cdot 6$ & 10.5 & $30 \cdot 0$ & $10 \cdot 8$ & 28.5 & $10 \cdot 4$ & $26 \cdot 4$ & $9 \cdot 0$ & $<0.001$ \\
\hline Saturated fat (E\%) & $13 \cdot 1$ & $3 \cdot 0$ & $12 \cdot 7$ & 3.0 & $12 \cdot 6$ & 2.9 & $12 \cdot 2$ & 3.0 & $11 \cdot 3$ & $2 \cdot 7$ & $<0.001$ \\
\hline \multicolumn{12}{|c|}{ Energy-adjusted micronutrient intakes } \\
\hline $\mathrm{Ca}(\mathrm{mg} / 4.2 \mathrm{MJ}$ per d) & 435 & 144 & 456 & 141 & 505 & 163 & 529 & 174 & 538 & 147 & $<0.001$ \\
\hline Folate $(\mu \mathrm{g} / 4.2 \mathrm{MJ}$ per $\mathrm{d})$ & 115 & 38 & 130 & 42 & 143 & 59 & 152 & 50 & 169 & 51 & $<0.001$ \\
\hline Fe $(\mathrm{mg} / 4.2 \mathrm{MJ}$ per d) & $5 \cdot 1$ & $1 \cdot 1$ & $5 \cdot 2$ & 1.0 & 5.5 & 1.4 & $5 \cdot 6$ & 1.2 & $5 \cdot 9$ & 1.4 & $<0.001$ \\
\hline $\mathrm{Mg}(\mathrm{mg} / 4.2 \mathrm{MJ}$ per $\mathrm{d})$ & 152 & 31 & 166 & 25 & 174 & 35 & 186 & 33 & 197 & 36 & $<0.001$ \\
\hline $\mathrm{K}(\mathrm{mg} / 4 \cdot 2 \mathrm{MJ}$ per $\mathrm{d})$ & 1473 & 294 & 1568 & 269 & 1641 & 389 & 1731 & 344 & 1779 & 329 & $<0.001$ \\
\hline Riboflavin (mg/4.2 MJ per d) & 0.67 & 0.22 & 0.68 & 0.19 & 0.71 & 0.22 & 0.76 & 0.24 & 0.74 & 0.19 & $<0.001$ \\
\hline Thiamin (mg/4.2 MJ per d) & 0.48 & 0.19 & 0.48 & 0.15 & 0.47 & 0.14 & 0.48 & 0.14 & 0.48 & 0.13 & 0.957 \\
\hline Vitamin A (RE/4.2 MJ per d) & 455 & 380 & 446 & 338 & 450 & 297 & 495 & 323 & 534 & 496 & 0.019 \\
\hline Vitamin $B_{6}(\mu \mathrm{g} / 4 \cdot 2 \mathrm{MJ}$ per $\mathrm{d})$ & 697 & 377 & 755 & 318 & 763 & 354 & 854 & 367 & 882 & 367 & $<0.001$ \\
\hline Vitamin $B_{12}(\mu \mathrm{g} / 4.2 \mathrm{MJ}$ per $\mathrm{d})$ & $2 \cdot 3$ & 1.9 & $2 \cdot 1$ & 1.3 & $2 \cdot 2$ & $2 \cdot 1$ & $2 \cdot 6$ & $2 \cdot 0$ & 2.5 & 1.5 & 0.030 \\
\hline Vitamin $\mathrm{C}(\mathrm{mg} / 4.2 \mathrm{MJ}$ per $\mathrm{d})$ & 42 & 27 & 44 & 28 & 48 & 31 & 53 & 31 & 56 & 32 & $<0.001$ \\
\hline Vitamin $E(\mathrm{mg} / 4.2 \mathrm{MJ}$ per d) & $5 \cdot 8$ & 2.5 & $6 \cdot 1$ & $2 \cdot 3$ & $6 \cdot 1$ & $2 \cdot 0$ & $6 \cdot 2$ & $2 \cdot 0$ & $6 \cdot 8$ & 2.5 & $<0.001$ \\
\hline
\end{tabular}

$E \%$, energy percentage; $R E$, retinol equivalents.

*Dietary intakes are based on average intake of two $24 \mathrm{~h}$ recalls.

tDutch Healthy Diet index score based on eight components without components physical activity and acidic foods and drinks, with a total score ranging from 0 points (no adherence to Dutch dietary guidelines 2006) to 80 points (maximum adherence).

fLow education = primary school, vocational and lower general secondary education; moderate=higher secondary education and intermediate vocational training; high = higher vocational education and university.

associated whereas dietary fibre and vegetable protein were positively associated with the DHD15-index score, and these trends remained significant after energy adjustment $(P<0.05)$. For the micronutrients $\mathrm{Ca}$, folate, $\mathrm{Fe}, \mathrm{Mg}$, $\mathrm{K}$, vitamin $\mathrm{B}_{6}$ and vitamin $\mathrm{C}$, significant positive trends were observed across quintiles of the DHD15-score, both crude and after energy adjustment. Thiamin was inversely associated with the index score, but this association disappeared after energy adjustment. For the micronutrients riboflavin, vitamin $\mathrm{A}$, vitamin $\mathrm{B}_{12}$ and vitamin $\mathrm{E}$, significant positive associations were observed for the energyadjusted intakes, but not for the unadjusted intakes.

The mean DHD15-index score based on FFQ data was 15.5 points higher than that based on $24 \mathrm{hR}$ data $(P<0.001$; Table 4; online supplementary material, Supplemental Fig. 1). The correlation between the DHD15index scores based on $24 \mathrm{hR}$ and FFQ data was 0.58 (95\% CI
$0.53,0.62)$, also after energy adjustment (0.56, $95 \%$ CI 0.52 , 0.61). The correlations between the component scores based on FFQ and $24 \mathrm{hR}$ data ranged between 0.14 and $0 \cdot 65$. The lowest correlations were observed for the components legumes and red meat, while the highest correlations were seen for tea and alcohol. For most components mean component scores were higher based on FFQ data compared with 24 hR data $(P<0 \cdot 001)$. Largest differences in mean component score were seen for legumes $(5.0$ points difference) and fish ( 3.8 points difference). Results from cross-classification showed that $78 \%$ of the population was classified into the same or neighbouring quintile and only $1 \%$ was classified into the opposite quintile, with Kendall's $\tau_{\mathrm{b}}$ coefficient of $0.41(95 \%$ CI $0.36,0 \cdot 45)$.

The mean DHD15-index score based on the FFQ was also significantly higher for women than men (mean difference 9.5 points). Significant differences between men 
Table 4 Mean scores (and standard deviations) of the Dutch Healthy Diet index 2015 (DHD15-index) and its components based on two $24 \mathrm{~h}$ recalls $(24 \mathrm{hR}$ ) and on an FFQ, and partial correlation scores (and $95 \%$ confidence intervals) between the two scores, in 885 Dutch men and women aged $20-75$ years

\begin{tabular}{|c|c|c|c|c|c|c|}
\hline & \multicolumn{2}{|c|}{$24 \mathrm{hR}$} & \multicolumn{2}{|c|}{ FFQ } & \multirow[b]{2}{*}{ Correlation* $^{*}$} & \multirow[b]{2}{*}{$95 \% \mathrm{Cl}$} \\
\hline & Mean & SD & Mean & SD & & \\
\hline DHD15-index $†$ & 73.7 & $16 \cdot 9$ & $89 \cdot 2$ & $15 \cdot 4$ & 0.56 & $0.52,0.61$ \\
\hline 1. Vegetables & $6 \cdot 2$ & $3 \cdot 2$ & $6 \cdot 8$ & $2 \cdot 7$ & 0.33 & $0.27,0.39$ \\
\hline 2. Fruit & $6 \cdot 2$ & $3 \cdot 7$ & $7 \cdot 1$ & $3 \cdot 4$ & 0.55 & $0.50,0.59$ \\
\hline 3. Wholegrain products & $5 \cdot 7$ & $2 \cdot 7$ & $5 \cdot 8$ & $2 \cdot 0$ & 0.32 & $0.26,0.38$ \\
\hline 4. Legumes & 0.8 & $2 \cdot 6$ & $5 \cdot 8$ & 4.5 & 0.14 & $0.07,0.20$ \\
\hline 5. Nuts & $2 \cdot 6$ & 3.9 & 3.9 & $3 \cdot 6$ & 0.32 & $0.26,0.37$ \\
\hline 6. Dairy & $6 \cdot 0$ & $3 \cdot 2$ & $6 \cdot 5$ & $3 \cdot 1$ & 0.29 & $0.23,0.35$ \\
\hline 7. Fish & $2 \cdot 2$ & $3 \cdot 8$ & $6 \cdot 1$ & $3 \cdot 1$ & 0.26 & $0.19,0.32$ \\
\hline 8. Tea & $5 \cdot 8$ & 4.0 & 3.6 & 3.5 & 0.65 & $0.61,0.69$ \\
\hline 9. Fats and oils & $6 \cdot 2$ & 4.5 & $6 \cdot 8$ & 4.0 & 0.33 & $0.27,0.39$ \\
\hline 10. Red meat & 8.6 & $3 \cdot 0$ & $9 \cdot 1$ & $2 \cdot 1$ & $0 \cdot 16$ & $0.10,0.23$ \\
\hline 11. Processed meat & $4 \cdot 3$ & 4.0 & $6 \cdot 0$ & $3 \cdot 2$ & 0.40 & $0.34,0.45$ \\
\hline 12. Sweetened beverages and fruit juices & 5.8 & $4 \cdot 0$ & $6 \cdot 4$ & $3 \cdot 4$ & 0.51 & $0.46,0.56$ \\
\hline 13. Alcohol & $7 \cdot 1$ & 4.0 & $7 \cdot 7$ & $3 \cdot 6$ & 0.60 & $0.56,0.64$ \\
\hline 14. Sodium & $6 \cdot 2$ & 3.4 & 7.9 & $2 \cdot 7$ & 0.21 & $0.14,0.27$ \\
\hline
\end{tabular}

Only total DHD15-index score was normally distributed (Pearson correlation).

${ }^{*}$ Adjusted for energy intake as assessed by $24 \mathrm{hR}$.

†DHD15-index score ranging from 0 to 140 points.

and women in component scores based on FFQ data were largely similar to the differences between men and women based on $24 \mathrm{hR}$ data (online supplementary material, Supplemental Table 1). Associations and trends observed across quintiles of DHD15-index score based on FFQ data with participant characteristics, macronutrient and energyadjusted micronutrient intakes showed similar results to those based on $24 \mathrm{hR}$ data (online supplementary material, Supplemental Table 2). The only exception was energyadjusted vitamin $\mathrm{B}_{12}$ where a positive trend across quintiles of DHD15-index was observed based on $24 \mathrm{hR}$ data but not with FFQ data.

\section{Discussion}

The DHD15-index score assesses adherence to the Dutch dietary guidelines 2015 and is able to rank participants according to their adherence, as was reflected by the variation in scores of the individual components of the index and the normally distributed total score. The index was positively associated with age, supplement use, fibre intake and nutrient density, and inversely associated with BMI, energy, total and saturated fat intakes. The most pronounced differences in score based on FFQ compared with $24 \mathrm{hR}$ data were found in the components reflecting episodically consumed foods such as fish, but associations of the DHD15-index with participants' characteristics and nutrient intakes were similar for the scores based on $24 \mathrm{hR}$ data and on FFQ data.

The DHD15-index score was developed as an update of the previously developed DHD-index reflecting adherence to the Dutch dietary guidelines of 2006. Therefore we kept the design aspects of this updated score similar to the DHD-index: the different components reflected the guidelines as closely as possible, for each component a minimum score of 0 and a maximum score of 10 points could be allotted, and intakes between the minimum and maximum were scored proportionally. Contrary to the dietary guidelines of 2006 , the guidelines of 2015 are formulated in terms of foods ${ }^{(10)}$. Only foods and food groups with sufficient scientific evidence for an effect on chronic diseases were included in the dietary guidelines. A consequence of this approach is that the dietary guidelines do not cover the complete dietary intake and recommended intakes in the guidelines apply to the general population. However, subgroups might benefit from a higher or lower intake of a food group to meet specific nutrient recommendations. For example, vegetarians might benefit from a higher legume or nut intake to meet recommended protein intake. This applies to indices based on both foods and nutrients as well, such as the Healthy Eating Index-2010. It should also be noted that within food groups there is still room for discussion about whether all foods within that food group should be included. For example, for dairy it could be argued that only low-fat dairy should be included as some studies show more favourable health effects for low-fat dairy compared with total dairy ${ }^{(23,24)}$. However, as the evidence is ambiguous and the debate is still ongoing, the Health Council of the Netherlands decided to set the guideline for total dairy $^{(9)}$ and we stayed as close as possible to the guidelines.

To quantify the guidelines additional information from additional documents from the Health Council of the Netherlands (background documents) ${ }^{(18-21)}$ and interpretation by experts was sometimes necessary. The evidence regarding intake levels at which adverse health effects occur, as described in the background documents, 
was used to set threshold values (i.e. the intake that deserves 0 points). This could be done for the moderation components red meat, processed meat, sweetened beverages and fruit juices, and alcohol. For example, according to the background document, an intake of $250 \mathrm{~g}$ of sweetened beverages and fruit juices daily is associated with an increased risk of weight gain and therefore the threshold value for this component was set at $250 \mathrm{~g} / \mathrm{d}$. For alcohol, adverse health effects associated with alcohol intake occur at different intake levels for men and women, therefore we set a different threshold values for men and women. For the component salt and the ratio components wholegrain products and fats and oils, there was not enough information to set an evidence-based threshold value. For those components the threshold value was based on the 85th percentile of the intake distribution based on two-day averages of the Dutch reference population ${ }^{(17)}$. This was also done for the DHD-index and is comparable to other indices such as the Healthy Eating Index-2010 ${ }^{(25)}$. For the ratio components the cut-off value was based on the 15th percentile of this intake distribution as there was no information on the ratio that deserves the maximum score. We used the information regarding standard portion sizes of the Netherlands Nutrition Cen$\operatorname{tre}^{(16)}$ for the components legumes, dairy, fish, tea and red meat, as the guidelines do not specify the recommended intake or only in number of servings.

The DHD15-index score based on $24 \mathrm{hR}$ data showed a moderate correlation $(0.56,95 \%$ CI $0.52,0.61)$ with the DHD15-index score based on FFQ data and is comparable with the correlation found for the initial DHD-index $(0 \cdot 48$, $95 \%$ CI $0.33,0.61)^{(1)}$. Ranking of participants showed moderate agreement as indicated by Kendall's $\tau_{\mathrm{b}}$ coefficient and fairly good concordance as $78 \%$ was ranked in the same or neighbouring quintile and only $1 \%$ in the opposite quintile. The cut-off and threshold values for the scores are absolute levels of intakes. We assume that a $24 \mathrm{hR}$ is more suitable to estimate dietary intakes on a group level as the used FFQ is designed to cover at least $90 \%$ of energy intake, but not able to capture $100 \%$ of the total intake ${ }^{(14)}$. However, several components are episodically consumed foods including fish, legumes and nuts. Using two-day averages of the $24 \mathrm{hR}$ can result in excess zeros and maximum scores, whereas an FFQ is better able to assess usual intakes of these episodically consumed foods because it assesses foods eaten during a longer period of time. This could be one explanation for the low correlations seen for these components when comparing the component scores based on $24 \mathrm{hR}$ and FFQ data. Other reasons for the low correlations between the scores based on the two methods are the biases inherent to the $24 \mathrm{hR}$ (e.g. high day-to-day variability) and FFQ (e.g. aggregation of food items, standard portion sizes) ${ }^{(26)}$. Surprisingly, also red meat showed a very low correlation and appeared to be an episodically consumed food in this health-conscious population. Mean intakes were substantially lower than the intake of the Dutch reference population, which could not be explained by a difference in number of non-consumers. A possible alternative to better estimate these episodically consumed foods would be using $24 \mathrm{hR}$ with an additional short propensity questionnaire as also advised for surveillance ${ }^{(27)}$. Additionally, the FFQ used in the present study was not able to distinguish between unsalted and salted nuts, and between types of tea, whereas the $24 \mathrm{hR}$ is able to make these distinctions. Both methods were not able to distinguish between types of coffee (filtered $v$. unfiltered). In future studies, an adapted FFQ able to distinguish between types of nuts, tea and coffee as well as an adapted $24 \mathrm{hR}$ to assess type of coffee should be used.

Other limitations of the used dietary assessment methods should also be considered. First, for both the $24 \mathrm{hR}$ and the FFQ, it is known that estimates for $\mathrm{Na}$ intake are biased and usually underestimated because information on salt added during cooking and at the dinner table is lacking. By reducing the cut-off level by $20 \%$ we tried to adjust for this, but realize this decreases variation between people and thus results on the sodium component should be interpreted with caution. Ideally, Na intake is estimated based on $24 \mathrm{~h}$ urinary- $\mathrm{N}$, which is considered the gold standard for estimating $\mathrm{Na}$ intake ${ }^{(28)}$. Second, for alcohol intake it was not possible to assess binge drinking with only two $24 \mathrm{hR}$ and the used FFQ. Finally, a difficulty arises in the handling of mixed foods (i.e. foods consisting of several (types of) ingredients). These mixed foods were broken down into their ingredients as coded by the Dutch Food Composition Table ${ }^{(13)}$ and the individual ingredients were used in the calculation of the food intakes. However, some foods in the Dutch Food Composition Table still consist of several different ingredients from different food groups. For these mixed foods, we included the food if more than half of the weight of the mixed food consisted of a food group of one of the components. For example, vegetables on pizza (component vegetables), sausage roll (processed meat) and pea soup (legumes) are not included in calculation of food intake, but porridge is ( $\geq 50 \%$ dairy).

The DHD15-index score presented in the current study was designed to capture the dietary pattern of the general Dutch population. The components of the DHD15-index are familiar components of Western dietary patterns and similar to components of several well-known and much used indices such as the Healthy Eating Index-2010 (vegetables, fruit, grains, dairy, alcohol, salt, fats and oils, and the components meat, fish, nuts and legumes in the protein foods) ${ }^{(25)}$ and the Mediterranean Diet Score (vegetables, fruits, legumes, cereals, dairy, meat, alcohol, and fats and oils ${ }^{(29)}$. However, it might be that for ethnic minorities with non-Dutch eating habits the score is limited in its use ${ }^{(30)}$. Furthermore, we evaluated the DHD15-index score in a population that might not be representative of the general Dutch population, as 
participants had in general a high level of education. Also, the high proportion of supplement users could indicate that this population is health-conscious. Therefore, we used the intake distribution of the Dutch reference population $^{(17)}$ for the intake-based threshold values in the development of the score instead of the intake distribution of our study population. This also has the advantage that results of future studies can be compared as the same threshold values are used.

Evaluation of indices is necessary to establish whether an index is suitable for further use. In the present study, several types of evaluation were carried out. First of all, we examined the relationship of the DHD15-index with nutrient intakes and observed positive trends between the DHD15-index score and energy-adjusted micronutrient intakes. This indicates that participants with higher DHD15-index scores have a more nutrient-dense diet. We also observed an inverse association with total energy intake, total fat intake and saturated fat intake, and a positive relationship with fibre intake, also suggesting that a higher DHD15-index score indicates a healthier diet. Second, construct validity was examined by assessing the relationship between the DHD15-index score and participants' characteristics such as age, educational level and supplement use. Although the trend observed was not significant, the proportion of highly educated participants increased with higher DHD15-index scores whereas the proportion of lower educated participants decreased. Additionally, supplement users, older participants and participants with a lower BMI had higher DHD15-index scores. Also, the variation in total score and the individual component scores indicates discriminative power of the DHD15-index. Lastly, comparability of the index based on different dietary assessment instruments was satisfactory. In addition, we saw an acceptable correlation between the DHD15-index score and the previously validated DHDindex score based on the 2006 guidelines. Based on these observations we think that the DHD15-index is a good measure of diet quality. Further evaluation steps include assessing the relationship between the DHD15-index and chronic diseases and mortality and its ability to monitor trends in dietary intake over time. As energy intake and BMI are inversely associated with the DHD15-index score, energy adjustment should be considered when studying diet-disease associations to be able to distinguish between effects from energy intake and the effects of diet quality as reflected by the DHD15-index score.

\section{Conclusion}

The DHD15-index score assesses adherence to the Dutch dietary guidelines of 2015 and is an indicator of diet quality as it is positively associated with nutrient density. Both $24 \mathrm{hR}$ and FFQ data can be used to assess the DHD15-index score, resulting in some differences in individual components but an acceptable correlation between the total scores. In future research, the DHD15index score can be used to study associations between diet quality and chronic diseases.

\section{Acknowledgements}

Acknowledgements: The authors would like to thank Rianne Weggemans and Caroline Spaaij from the Dutch Health Council for their help in interpreting the Dutch dietary guidelines in order to create the DHD15-index. Financial support: This research received no specific grant from any funding agency in the public, commercial or notfor-profit sectors. Conflict of interest: None. Authorship: All authors were involved in the development of the presented index score. M.L. conducted the statistical analyses. E.J.M.F. and A.G. contributed to the analyses and interpretation of the data. All named authors contributed to the drafting of the paper, all critically reviewed its content and have approved the final version submitted for publication. Ethics of human subject participation: This study was conducted according to the guidelines laid down in the Declaration of Helsinki and all procedures involving human subjects/patients were approved by the Medical Ethical Committee of Wageningen University. Written informed consent was obtained from all participants.

\section{Supplementary material}

To view supplementary material for this article, please visit https://doi.org/10.1017/S136898001700091X

\section{References}

1. van Lee L, Geelen A, van Huysduynen EJ et al. (2012) The Dutch Healthy Diet index (DHD-index): an instrument to measure adherence to the Dutch Guidelines for a Healthy Diet. Nutr J 11, 49.

2. Sluik D, van Lee L, Geelen A et al. (2014) Alcoholic beverage preference and diet in a representative Dutch population: the Dutch national food consumption survey 2007-2010. Eur J Clin Nutr 68, 287-294.

3. Struijk EA, Beulens JW, May AM et al. (2014) Dietary patterns in relation to disease burden expressed in disabilityadjusted life years. Am J Clin Nutr 100, 1158-1165.

4. Struijk EA, May AM, Beulens JW et al. (2014) Adherence to the Dutch Guidelines for a Healthy Diet and cancer risk in the European Prospective Investigation into Cancer and Nutrition-Netherlands (EPIC-NL) cohort. Public Health Nutr 17, 2546-2553.

5. van Lee L, Feskens EJ, Hooft van Huysduynen EJ et al. (2013) The Dutch Healthy Diet index as assessed by $24 \mathrm{~h}$ recalls and FFQ: associations with biomarkers from a crosssectional study. J Nutr Sci $\mathbf{2}$, e40.

6. van Lee L, Geelen A, Kiefte-de Jong JC et al. (2016) Adherence to the Dutch dietary guidelines is inversely associated with 20 -year mortality in a large prospective cohort study. Eur J Clin Nutr 70, 262-268.

7. Struijk EA, May AM, Wezenbeek NL et al. (2014) Adherence to dietary guidelines and cardiovascular disease risk in the EPIC-NL cohort. Int J Cardiol 176, 354-359. 
8. Fransen HP, Beulens JW, May AM et al. (2015) Dietary patterns in relation to quality-adjusted life years in the EPICNL cohort. Prev Med 77, 119-124.

9. Health Council of the Netherlands (2015) Dutch Dietary Guidelines 2015. Publication no. 2015/24. The Hague: Health Council of the Netherlands.

10. Kromhout D, Spaaij CJ, de Goede J et al. (2016) The 2015 Dutch food-based dietary guidelines. Eur J Clin Nutr 70, 869-878.

11. van Lee L, Geelen A, Hooft van Huysduynen EJ et al. (2016) Associations between company at dinner and daily diet quality in Dutch men and women from the NQplus study. Eur J Clin Nutr 70, 1368-1373.

12. Conway JM, Ingwersen LA, Vinyard BT et al. (2003) Effectiveness of the US Department of Agriculture 5-step multiple-pass method in assessing food intake in obese and nonobese women. Am J Clin Nutr 77, 1171-1178.

13. NEVO-tabel (2011) Dutch Food Composition Table 2011/ version 3. The Hague: National Institute for Public Health and the Environment/Netherlands Nutrition Centre.

14. Siebelink E, Geelen A \& de Vries JH (2011) Self-reported energy intake by FFQ compared with actual energy intake to maintain body weight in 516 adults. Br J Nutr 106, 274-281.

15. Streppel MT, de Vries JH, Meijboom S et al. (2013) Relative validity of the food frequency questionnaire used to assess dietary intake in the Leiden Longevity Study. Nutr J 12, 75.

16. Netherlands Nutrition Centre (2016) Richtlijnen Schiff van Viff. The Hague: Netherlands Nutrition Centre.

17. van Rossum CTM, Fransen HP, Verkaik-Kloosterman J et al. (2011) Dutch National Food Consumption Survey 20072010: Diet of Children and Adults 7 to 69 Years. Bilthoven: National Institute for Public Health and the Environment.

18. Health Council of the Netherlands (2015) Dutch Dietary Guidelines 2015 - Background Document Legumes. Publication no. A15/18. The Hague: Health Council of the Netherlands.

19. Health Council of the Netherlands (2015) Dutch Dietary Guidelines 2015 - Background Document Meat. Publication no. A15/27. The Hague: Health Council of the Netherlands.
20. Health Council of the Netherlands (2015) Dutch Dietary Guidelines 2015 - Background Document SugarSweetened Beverages. Publication no. A15/08. The Hague: Health Council of the Netherlands.

21. Health Council of the Netherlands (2015) Dutch Dietary Guidelines 2015 - Background Document Alcohol. Publication no. A15/05. The Hague: Health Council of the Netherlands.

22. van Rossum CTM, Buurma-Rethans EJM, Fransen HP et al. (2012) Zoutconsumptie van kinderen en volwassenen in Nederland Resultaten uit de Voedselconsumptiepeiling 2007-2010. Bilthoven: National Institute for Public Health and the Environment.

23. Aune D, Norat T, Romundstad P et al. (2013) Dairy products and the risk of type 2 diabetes: a systematic review and dose-response meta-analysis of cohort studies. Am J Clin Nutr 98, 1066-1083.

24. Dong JY, Zhang L, He K et al. (2011) Dairy consumption and risk of breast cancer: a meta-analysis of prospective cohort studies. Breast Cancer Res Treat 127, 23-31.

25. Guenther PM, Casavale KO, Reedy J et al. (2013) Update of the Healthy Eating Index: HEI-2010. J Acad Nutr Diet 113, 569-580.

26. Willett WC (2013) Nutritional Epidemiology, 3rd ed. New York: Oxford University Press.

27. de Boer EJ, Slimani N, van 't Veer P et al. (2011) The European Food Consumption Validation Project: conclusions and recommendations. Eur J Clin Nutr 65, Suppl. 1, S102-S107.

28. Brown IJ, Tzoulaki I, Candeias V et al. (2009) Salt intakes around the world: implications for public health. Int $J$ Epidemiol 38, 791-813.

29. Trichopoulou A, Costacou T, Bamia C et al. (2003) Adherence to a Mediterranean diet and survival in a Greek population. N Engl J Med 348, 2599-2608.

30. Dekker LH, Nicolaou M, van Dam RM et al. (2015) Socioeconomic status and ethnicity are independently associated with dietary patterns: the HELIUS-Dietary Patterns study. Food Nutr Res 59, 26317. 